\title{
TARGET VALUE DESIGN NA GESTÃO DO PROCESSO DE PROJETO POR MEIO DE SIMULAÇÃO: DIFUSÃO DE CONCEITOS E REFLEXÕES TEÓRICAS
}

\section{TARGET VALUE DESIGN IN THE DESIGN MANAGEMENT PROCESS THROUGH SIMULATION: DIFUSION OF CONCEPTS AND THEORETICAL INSIGHTS}

\author{
Carolina Asensio Oliva ${ }^{1}$ \\ Universidade Estadual de Campinas, Campinas, SP, Brasil, carol_oliva@yahoo.com.br \\ Reymard Savio Sampaio de Melo ${ }^{2}$ \\ Universidade Estadual de Campinas, Campinas, SP, Brasil, reymardsavio@gmail.com \\ Ariovaldo Denis Granja ${ }^{3}$ \\ Universidade Estadual de Campinas, Campinas, SP, Brasil, adgranja@fec.unicamp.br
}

\section{Resumo}

O custo tem um impacto significante não só no processo de projeto, mas também na solução arquitetônica apresentada. O Target Value Design (TVD), pode se apresentar como uma abordagem promissora para direcionar o processo de projeto pelo custo e pelas percepções de valor do cliente ou usuário final. Esta pesquisa almejou disseminar conceitos do TVD junto a agentes participantes na gestão do processo de projeto de empreendimentos imobiliários e contribuir para a reflexão teórica sobre a sua adoção neste meio. O método de pesquisa consistiu em simulações-piloto em meio acadêmico para adaptações iniciais e simulações posteriores em empresa de incorporação imobiliária. As simulações se deram em duas rodadas, a primeira simulando o ambiente tradicional de Design-Bid-Build (DBB) e a segunda utilizando o TVD. Os resultados provenientes da segunda rodada (TVD), onde foi imposta uma restrição de custo, acabaram levando a uma aparente simplificação do modelo. O TVD demanda mudanças no processo de projeto, e uma das mais desafiadoras é considerar o custo como parâmetro de entrada no processo, em vez de ser uma mera consequência do mesmo.

Palavras-chave: Target Value Design. Gestão do Processo de Projeto. Simulação.

\begin{abstract}
Cost have a significant impact not only in the design process itself but also in the final architectural solution. Target Value Design (TVD) can be a promising approach to make cost and value in the client's or end-user's perception drive the design process. The research aimed to introduce basic TVD concepts for teams involved in the design process management of real estate products and to allow theoretical insights of its adoption in this situation. The research method consisted of a simulation in both academic and corporate environment, in two rounds, the first one simulated the Design-Bid-Build (DBB) process and de second one using the TVD approach. The results from the second round (TVD), where a cost constraint was imposed, led to apparent simplification of the model. TVD demands change in the design process, and the most challenging one is the cost as a driver to design process, instead of an output of it.
\end{abstract}

Keywords: Target Value Design. Design Process. Simulation.

How to cite this article:

OLIVA, Carolina; MELO, Reymard Savio Sampaio de; GRANJA, Ariovaldo Denis. Target Value Design na gestão do processo de projeto por meio de simulação: difusão de conceitos e reflexões teóricas. PARC Pesquisa em Arquitetura e Construção, Campinas, SP, v. 6, n. 1, p. 4-15, jan./mar. 2015. ISSN 1980-6809. 


\section{Introdução}

Atualmente no Brasil, o mercado de produtos imobiliários passa por um momento de incertezas. Empresas atuantes neste segmento tentam prognosticar a demanda por produtos imobiliários, com repercussões na sua política de preços. Normalmente, estes produtos são desenvolvidos num ambiente caracterizado por restrições orçamentárias e por fragmentação do processo de projeto. Soma-se a isso uma cultura de adversidade e proteção de interesses individuais em detrimento do resultado do empreendimento como um todo. Neste processo tradicional e recorrente, o custo é uma consequência do projeto desenvolvido.

Frequentemente, a fase de processo de projeto se dá dissociada da etapa de construção em produtos imobiliários. Incorporadoras, em geral, terceirizam grande parte da prestação de serviços e desenvolvimento do projeto. Práticas colaborativas entre os diversos agentes envolvidos não são tão comuns ou são incipientes. Numa apreciação dos trabalhos nacionais, Romano (2003) abordou esta questão sob a ótica de termos de referência. Outros se dedicaram a conceitos como a Engenharia Simultânea como forma de promover maior colaboração entre os envolvidos no processo de projeto (MELHADO et al; 2006). Por sua vez, Ceron (2011) analisou-a sob a perspectiva de custo e valor na arquitetura. Porém, pouca atenção tem sido direcionada para a influência do custo como parâmetro de entrada e indutor de criatividade ao longo do processo de projeto.

Por outro lado, a ferramenta estratégica Target Value Design (TVD) utiliza o valor na percepção do cliente e suas restrições orçamentárias como parâmetros norteadores do processo de projeto. Nos EUA, o TVD tem sido utilizado no contexto de empreendimentos educacionais e hospitalares como referencial teórico para a gestão do processo de projeto de forma integrada. Os resultados destas implantações têm reduzido a probabilidade de desvios de custos, mantendo os requisitos de valor na perspectiva dos clientes (BALLARD; REISER, 2004; MACOMBER et al., 2007; BALLARD, 2011; RYBKOWSKI et al, 2011; ZIMINA et al., 2012; DENEROLLE, 2013; DO et al, 2014)

O TVD tem sido reivindicado como uma adaptação do Custeio-meta (CM) para o setor da construção. Em que pese a existência de estudos sobre o CM, a abrangência de pesquisas do TVD no Brasil ainda é limitada. Portanto, a questão de pesquisa que norteou este artigo foi como difundir os conceitos do TVD junto a agentes atuantes em incorporação imobiliária, que desenvolvem seus produtos utilizando o sistema tradicional? Para tanto adaptou-se uma simulação na forma do TVD game já aplicado nos EUA (MUNANKAMI, 2012). A pesquisa teve como objetivo principal disseminar conceitos do TVD junto a agentes participantes na gestão do processo de projeto de empreendimentos imobiliários e contribuir para a reflexão teórica sobre a sua adoção neste meio.

\section{O Custeio-Meta e o Target Value Design (TVD)}

Para muitos autores, o Custeio-Meta (CM) tem suas origens na indústria automobilística japonesa no início dos anos 1960, como estratégia de redução de custos e manutenção dos resultados esperados (COOPER; SLAGMULDER, 1997; LIKER, 2004; JACOMIT; GRANJA, 2011). O gerenciamento de custos tradicional determina o custo do produto baseado no projeto e no custo de produção. O referencial teórico do $\mathrm{CM}$ inverte esta lógica: o custo-meta do produto é determinado antes do projeto e é baseado nas necessidades do cliente, no preço este cliente está disposto a pagar por tais benefícios e na margem de lucro definida estrategicamente (COOPER; SLAGMULDER, 1997; LIKER, 2004; PENNANEN; BALLARD; HAATELA, 2008) (Equação 1).

$$
\text { Custo-meta }=\text { Preço }- \text { Margem de Lucı (1) }
$$

O CM eleva as restrições orçamentárias para induzir criatividade e inovação no início do processo de projeto. Nesta lógica, as partes interessadas, entre as quais os projetistas, fornecedores e empreiteiros, trabalham de forma colaborativa na busca de soluções projetuais com o objetivo de garantir que o produto final tenha atributos representativos de valor na percepção do cliente/usuário, levando-se em consideração o custometa definido.

O CM pode ser considerado uma ferramenta estratégica inserida dentro da filosofia Lean de desenvolvimento de produtos. Segundo Cooper e Slagmulder (1997), o modelo tradicional difere do Lean pelo fato do processo de desenvolvimento não ser responsabilidade de uma equipe única, mas distribuída entre múltiplos departamentos de maneira integrada. Na manufatura, o processo tradicional normalmente desenvolve os seus produtos a partir do departamento de marketing, sendo então transferido para o departamento de engenharia, onde é convertido em especificações técnicas. Estas especificações são convertidas em diagramas e, quando o projeto está completo, ele é passado para a produção. Quando estes departamentos finalizam seu trabalho, o projeto é transferido para a engenharia de processos para revisão final (COOPER; SLAGMULDER, 1997). 
Nos EUA, o TVD vem sendo proposto como uma adaptação do CM para a indústria da construção civil (MACOMBER et al., 2007). O TVD pode ser entendido como uma abordagem de gerenciamento da filosofia Lean e, para que se obtenham os benefícios de forma eficiente, ele considera que o produto está inserido num contexto de Integrated Project Delivery (IPD) (AIA, 2007). Quando comparado ao TVD, o IPD se enquadra como uma ferramenta de entrega do empreendimento (project delivery) de modo mais amplo (DENEROLLE, 2013). No TVD, a construção civil é concebida como um sistema complexo que inclui: i) a definição do produto, ii) o empreendimento e suas fases de execução e iii) a entrega de maior valor agregado aos usuários finais, por meio de melhoria contínua e eliminação de perdas. (DENEROLLE, 2013).

É importante ressaltar que a organização da equipe, por si só, nem sempre é suficiente para a aplicação bemsucedida do TVD, uma vez que ele é fortemente baseado nos princípios do IPD (AIA, 2007). O IPD é um processo de projeto integrado, que utiliza os conhecimentos e especialidades de cada membro da equipe, visando às melhores soluções de forma integrada (AIA, 2007). No IPD, todos os envolvidos com o processo de desenvolvimento de produto trabalham de forma colaborativa como uma única equipe, o que pode representar um grande desafio para as partes interessadas no empreendimento (ZIMINA; BALLARD; PASQUIRE, 2012).

Estando o TVD e IPD tão conectados entre si, um grupo de pesquisadores desenvolveu mais profundamente os princípios norteadores para a aplicação do TVD, feita pelo Project Production Systems Laboratory (P SL). O trabalho desenvolvido por este grupo estabelece 17 princípios que norteiam a aplicação do TVD (BALLARD, 2011). É importante salientar que, até o momento, as evidências de aplicações bem-sucedidas do TVD nos EUA provêm de empreendimentos voltados para a educação e saúde e pressupõem estágios avançados de maturidade do IPD para utilização concomitante com o TVD, em ambientes altamente colaborativos. Elencados a seguir estão os princípios do TVD (BALLARD; 2011):

1. Com o auxílio dos prestadores de serviços principais, o cliente desenvolve e avalia o estudo de caso do empreendimento e decide se deve financiar um estudo de viabilidade; em parte baseado na lacuna entre o custo permissível de projeto e o custo de mercado (Jacomit e Granja, 2011, detalham as diferenças conceituais entre o custo-meta e o custo permissível, as quais fogem ao escopo desta pesquisa);
2. A análise do empreendimento é baseada na previsão do custo do ciclo de vida do edifício e seus benefícios, preferivelmente derivado de um modelo de operação. Ele inclui a especificação do custo permissível, ou seja, quanto o usuário quer e está disposto a pagar por benefícios ao longo do ciclo de vida do produto. Restrições orçamentárias são especificadas, como por exemplo, as limitações do usuário para arcar com o investimento exigido para obter estes benefícios;

3. O estudo de viabilidade envolve todos os membroschave (projetistas, construtores, partes interessadas do cliente) na equipe que irá entregar o projeto, caso os resultados do estudo de caso do empreendimento sejam positivos;

4. A viabilidade é avaliada por meio do alinhamento de fins (o que se quer), meios (projeto conceitual) e restrições (custo, tempo, entre outros parâmetros). O projeto é aprovado somente se este alinhamento é alcançado ou possível de ser alcançado durante o processo de projeto;

5. O estudo de viabilidade produz um orçamento detalhado e cronograma alinhados com escopo e parâmetros de qualidade;

6. O cliente é membro ativo e permanente da equipe de desenvolvimento e entrega do empreendimento (project delivery) e participa ativamente do processo de projeto;

7. Todos os membros da equipe entendem o conceito do empreendimento e a perspectiva de valor das partes interessadas;

8. Algumas formas de contratos relacionais, em contraponto aos transacionais, são usadas para alinhar interesses dos membros da equipe de projeto com os objetivos do empreendimento;

9. Regra fundamental: as metas de custos e cronograma não podem ser excedidas, e somente o cliente pode alterar o escopo, qualidade, custo ou cronograma;

10. As implicações de custo, qualidade e cronograma em soluções alternativas de projeto são discutidas pelos membros da equipe, antes da alocação de grandes investimentos pela equipe do empreendimento;

11. As estimativas de custos e orçamento são feitas continuamente por meio de colaboração verdadeira entre os membros da equipe das diversas disciplinas projetuais;

12. O Sistema Last Planner (BALLARD, 2000) é utilizado para coordenar ações entre a equipe;

13. As metas são estabelecidas como objetivos flexíveis a fim de estimular inovação; 
14. As metas de escopo e custo são alocadas nas equipes de TVD multidisciplinares, tipicamente divididas em sistemas: estrutural, hidráulico, elétrico; entre outros;

15. As equipes de TVD atualizam suas estimativas de custos frequentemente;

16. A estimativa de custos do projeto é atualizada frequentemente para refletir as atualizações das equipes de TVD;

17. A colocalização, ou seja, o trabalho das equipes num mesmo local, é fortemente aconselhada, pelo menos quando elas ainda forem recém-constituídas. Ela não precisa ser permanente; reuniões de equipes podem ser realizadas semanalmente, ou mais frequentemente, mediante necessidade.

Num projeto inserido no contexto do IPD, além de colaboração contínua de todos os agentes, os envolvidos também compartilham riscos e ganhos, de forma a incentivar a busca das soluções de maneira mais adequada, sem se distanciar dos objetivos e metas do produto (AIA; 2007) (Figura 1).

Diferentemente do processo tradicional, o IPD busca integrar os agentes desde a fase de concepção de projeto. Assim, soluções para a construtibilidade, por exemplo, podem ser consideradas já em estágios iniciais do projeto. Os riscos e margens de lucro são compartilhados, e isso acaba levando a um esforço extra dos envolvidos para atingir as metas estabelecidas previamente, no início do processo. Dentro desta lógica, as restrições de custo, prazo, entre outras, passam a ser assimiladas como indutores de criatividade e inovação, para que não ocorra redução de escopo e consequente redução de entrega de valor para o cliente.

Figura 1 - Processo de projeto tradicional comparado com o IPD

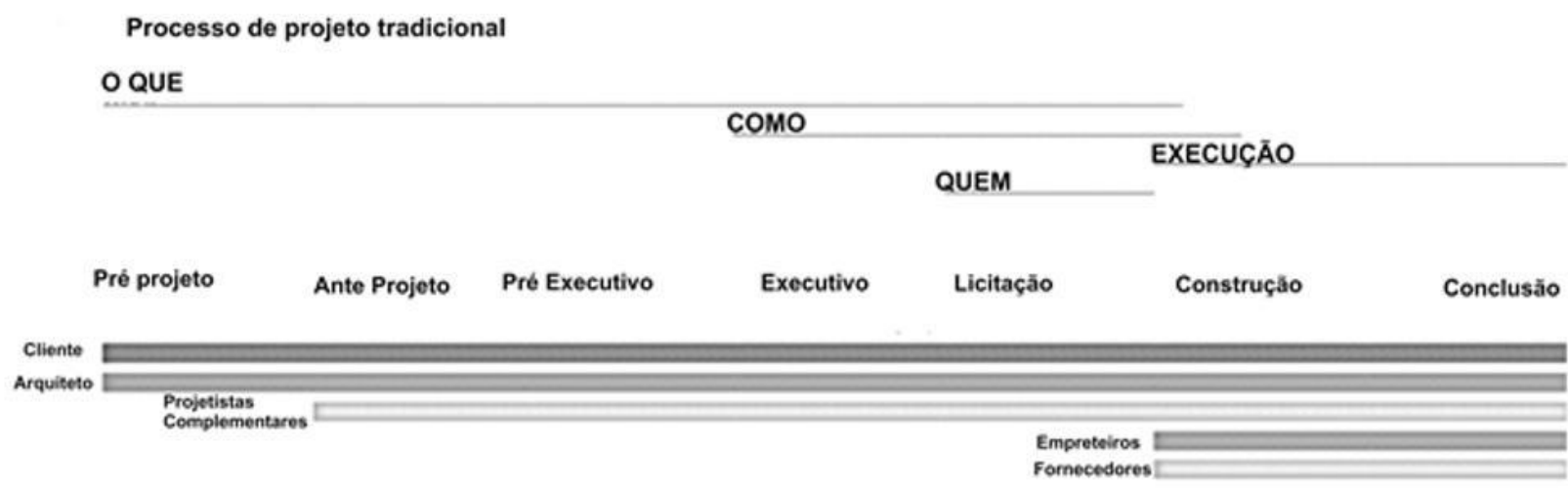

Processo de projeto integrado (IPD)

OQUE

COMO

QUEM

EXECUÇÃO

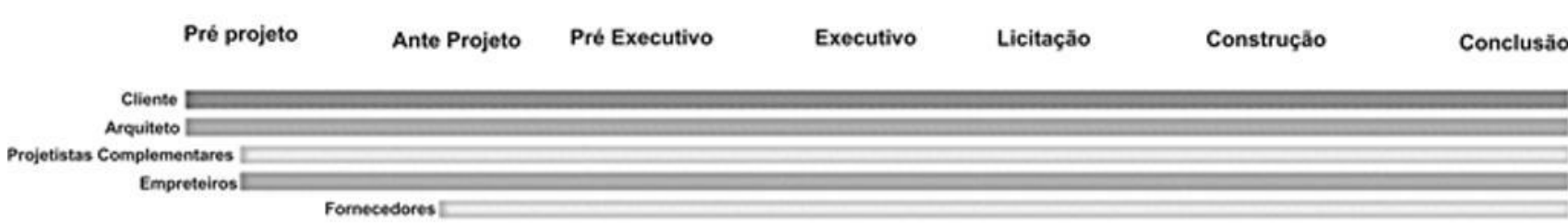

Fonte: Adaptado de AIA (2007).

\section{Método de pesquisa}

A estratégia de pesquisa adotada foi a simulação. Simulações fazem uso de um modelo com o intuito de representar as características essenciais de uma realidade (FELLOWS; LIU, 2008). Podem envolver sistemas ou processos. No caso desta pesquisa, a simulação envolve o processo de projeto com a incorporação de conceitos do TVD. Para se realizar a simulação, utilizou-se o TVD game, simulado com participantes no Nepal (MUNANKAMI, 2012), com adaptações. 
As simulações ocorreram no meio acadêmico e junto a agentes em uma empresa de incorporação, com foco em seu processo de projeto de empreendimentos imobiliários. No meio acadêmico, a simulação teve o caráter de simulação-piloto, visando promover adequações ao contexto nacional. Docentes e discentes dos cursos de Arquitetura e Urbanismo e de Engenharia Civil de uma Instituição de Ensino Superior compuseram os participantes acadêmicos para a primeira simulação. Projetistas, gestores e profissionais da área de incorporação da empresa estiveram envolvidos na segunda simulação. Os autores da pesquisa atuaram como facilitadores.

Em cada simulação, respectivamente processo tradicional (DBB) e TVD, os participantes foram divididos em dois times. Por sua vez, cada time foi subdividido em dois grupos: o de projetistas e o de construtores. As simulações tiveram uma duração total de $30 \mathrm{~min}$, em cada rodada $(30 \mathrm{~min}$ para a rodada em DBB e 30min para a rodada em IPD). Cada time teve como objetivo projetar e construir uma torre que fosse capaz de suportar um pedaço de marshmallow no seu topo. A torre teria que alcançar exatos $50 \mathrm{~cm}$ na vertical e deveria ser autoportante, sem qualquer fixação auxiliar na bancada.

Um kit de fabricação foi então apresentado aos participantes, e consistia de: fita crepe, tesoura, pedaço de marshmallow, palitos, espetos, canudinhos e espaguete. Foi fornecida uma folha de projeto, onde os participantes tinham acesso a uma foto dos materiais disponíveis para construção (Figura 2), além de informações com relação às dimensões de tais materiais.

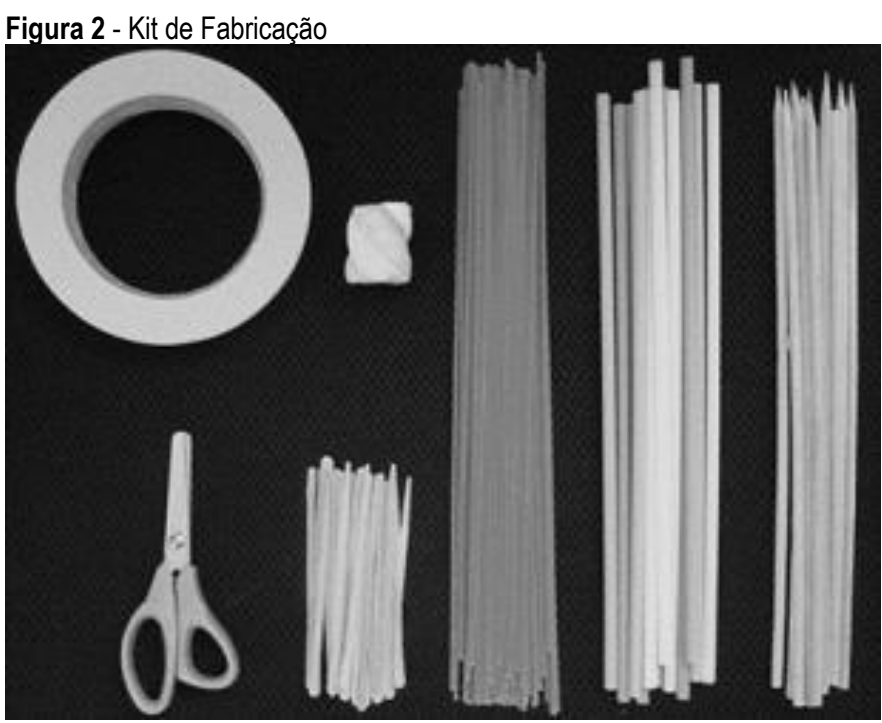

Fonte: Autores.

A primeira rodada simulou um método tradicional de entrega de empreendimentos, o Design-Bid-Build
(DBB) - Projetar-Licitar-Construir - no qual o custo é determinado a partir do projeto. Nesta rodada, os projetistas desenvolveram o projeto da torre sem qualquer tipo de interação com os construtores do seu respectivo time. Os facilitadores intervieram com o processo de projeto já em andamento, solicitando às equipes que a torre, que já estava sendo projetada, também deveria representar um marco icônico, ilustrando mudanças de escopo que frequentemente ocorrem no DBB. Após o projeto concluído e aceito pelo cliente, os construtores o receberam para executá-lo. Foi permitido consultar os projetistas do seu time em caso de dúvida de projeto.

Ao término da primeira rodada, uma discussão com todos os participantes foi realizada com o objetivo de comparar a experiência simulada com situações reais e introduzir a temática de custos na simulação, como uma das restrições do cliente. $\mathrm{O}$ custo como restrição do cliente foi introduzido para o início da segunda rodada (Tabela 1).

Tabela 1 - Custos de cada material empregado no projeto da torre em unidade monetárias fictícias (UM\$)

\begin{tabular}{cc}
\hline Materiais & Custo unitário (UM\$) \\
\hline Fio de espaguete & 1,00 \\
\hline Palito & 5,00 \\
\hline Canudo & 2,00 \\
\hline Espeto & 3,00 \\
\hline Fita crepe (por junta) & 0,50 \\
\hline
\end{tabular}

Fonte: Autores.

A segunda rodada se destinou a simular os conceitos do TVD no projeto da torre. Portanto, nesta rodada o custo passa a ser um parâmetro de entrada para o desenvolvimento do projeto, salvaguardados os requisitos de valor do cliente, pois é esta a principal base teórica do TVD. Nesta rodada, os facilitadores, exercendo o papel do cliente, comunicaram um custo permissível da torre para os times, antes do início do seu projeto. A definição do custo permissível se baseou nos custos levantados dos projetos da primeira rodada. Para se incentivar a indução de inovação e a criatividade, os facilitadores, mantiveram seus requisitos iniciais de valor, ou seja, a torre como símbolo icônico, e, ao mesmo tempo, comunicaram o custo permissível, abaixo do custo realizado pelos projetos na primeira fase (a definição do custo permissível é apresentada mais à frente na apresentação das simulações). $O$ desafio principal foi colocar os agentes envolvidos na situação de como entregar valor na perspectiva do cliente, levando-se em conta as suas restrições orçamentárias (custo permissível)

Incorporando mais conceitos e princípios do TVD, a colaboração e a troca de informações entre as equipes foram introduzidas nesta rodada. Construtores e 
projetistas trabalharam de forma integrada no projeto e na construção da torre nesta rodada, havendo feedback contínuo do cliente, representado pelos facilitadores. Ao final desta rodada, as torres foram apresentadas e custeadas novamente, para verificar se estavam dentro da restrição de custos imposta pelo cliente nesta rodada, ou seja, o custo permissível da torre, e uma nova discussão foi realizada com os participantes com relação à abordagem do TVD, quando comparada à abordagem tradicional da primeira rodada.

As simulações foram feitas de forma sequencial (primeiro os dois times participaram da rodada DBB e depois da rodada TVD), representando uma das limitações da simulação. Munankami (2012) relata que o jogo pode ser simulado no formato reverso (primeiro a rodada TVD e depois a rodada DBB), como forma de mitigar o efeito do aprendizado entre a primeira e segunda rodadas. Por outro lado, a utilização paralela e concomitante do sistema tradicional e do TVD também representaria dificuldades, na medida em que os dois grupos precisariam ter características bastante homogêneas para evitar viés.

\section{Dados coletados e análise}

Esta seção apresenta os resultados das simulações nos ambientes acadêmico e corporativo e respectivas análises.

\section{Simulações-piloto no meio acadêmico}

Os participantes das simulações-piloto no meio acadêmico foram divididos em dois times e seguiram os passos descritos anteriormente, realizando primeiro a simulação com o processo tradicional (DBB) e depois com o emprego do TVD. A Tabela 2 mostra os dados referentes a custos das torres nas duas rodadas para cada time.

As discussões com os participantes dos times sobre as simulações-piloto no meio acadêmico resultaram em algumas reflexões que nortearam a adoção de adequações para a realização posterior das simulações na empresa de incorporação imobiliária.

Tabela 2 - Custos das soluções projetuais nas simulações-piloto no meio acadêmico

\begin{tabular}{|c|c|c|c|c|c|c|c|c|c|}
\hline \multirow{3}{*}{ Materiais } & \multirow{3}{*}{$\begin{array}{l}\text { Custo } \\
\text { unitário } \\
\text { (UM\$) }\end{array}$} & \multicolumn{4}{|c|}{ Primeira Rodada - tradicional (DBB) } & \multicolumn{4}{|c|}{ Segunda Rodada - TVD } \\
\hline & & \multicolumn{2}{|c|}{ TIME 1} & \multicolumn{2}{|c|}{ TIME 2} & \multicolumn{2}{|c|}{ TIME 1} & \multicolumn{2}{|c|}{ TIME 2} \\
\hline & & $\begin{array}{l}\text { Número de } \\
\text { unidades }\end{array}$ & $\begin{array}{l}\text { Subtotal } \\
\text { (UM\$) }\end{array}$ & $\begin{array}{l}\text { Número de } \\
\text { unidades }\end{array}$ & $\begin{array}{l}\text { Subtotal } \\
\text { (UM\$) }\end{array}$ & $\begin{array}{l}\text { Número de } \\
\text { unidades }\end{array}$ & $\begin{array}{c}\text { Subtotal } \\
\text { (UM\$) }\end{array}$ & $\begin{array}{l}\text { Número de } \\
\text { unidades }\end{array}$ & $\begin{array}{c}\text { Subtotal } \\
\text { (UM\$) }\end{array}$ \\
\hline Fio de espaguete & 1,00 & 7 & 7,00 & 40 & 40,00 & 8 & 8,00 & 4 & 4,00 \\
\hline Palito & 5,00 & 0 & - & 0 & - & 0 & - & 0 & - \\
\hline Canudo & 2,00 & 2 & 4,00 & 8 & 16,00 & 4 & 8,00 & 2 & 4,00 \\
\hline Espeto & 3,00 & 3 & 9,00 & 2 & 6,00 & 0 & - & 3 & 9,00 \\
\hline Fita crepe (por junta) & 0,50 & 5 & 2,50 & 7 & 3,50 & 4 & 2,00 & 8 & 4,00 \\
\hline Subtotal & & & 22,50 & & 65,50 & & 18,00 & & 21,00 \\
\hline
\end{tabular}

\section{Discussões da rodada 1 no meio acadêmico - processo tradicional (DBB)}

1. O custo foi um parâmetro raramente mencionado durante o projeto, bem como as características dos materiais e eventuais técnicas construtivas;

2. Com a simulação em andamento, o cliente solicitou um novo requisito aos projetistas para a torre (marco icônico) com o projeto já em andamento, gerando retrabalho e aumento do tempo de duração da fase de projeto;

3. Durante a fase de construção, alguns detalhes relacionados ao projeto não estavam claros para o grupo de execução, ocasionando muitas consultas ao grupo de projeto e decorrentes revisões no projeto;

4. O conhecimento dos materiais se restringia à imagem e dimensões dos mesmos numa folha impressa, o que dificultou uma análise mais detalhada sobre a construtibilidade já na etapa de projeto (por exemplo, compatibilidade, encaixes possíveis, resistência, entre outros);

5. Não houve preocupação com uma distribuição consciente dos tempos nas fases de projeto e construção ao longo dos $30 \mathrm{~min}$. de simulação. Nenhum dos dois times conseguiu cumprir o prazo para projeto e construção da torre;

6. O tempo remanescente para a etapa de construção foi considerado curto pelos dois times;

\section{Discussões da rodada 2 no meio acadêmico - TVD}

7. Os facilitadores arbitraram um custo permissível de $\mathrm{UM} \$ 21,00$ para a torre; 
8. No início, o custo permissível para construção da torre tendeu a ser visto pelos participantes como um entrave para o processo de entrega de valor, principalmente com relação à torre se constituir num marco icônico;

9. Houve maior reflexão e preocupação com seleção de materiais com menor custo, para que o custo permissível não fosse ultrapassado;

10. Houve algumas reflexões sobre como se reduzir custos em atributos e materiais da torre que poderiam não agregar valor para o cliente.

Seguem modelos da torre gerados nas simulações (Figuras 3 e 4 ).

Figura 3- Soluções propostas pelos times na primeira rodada (processo tradicional - DBB) - Time 1 lado direito, Time 2 lado esquerdo

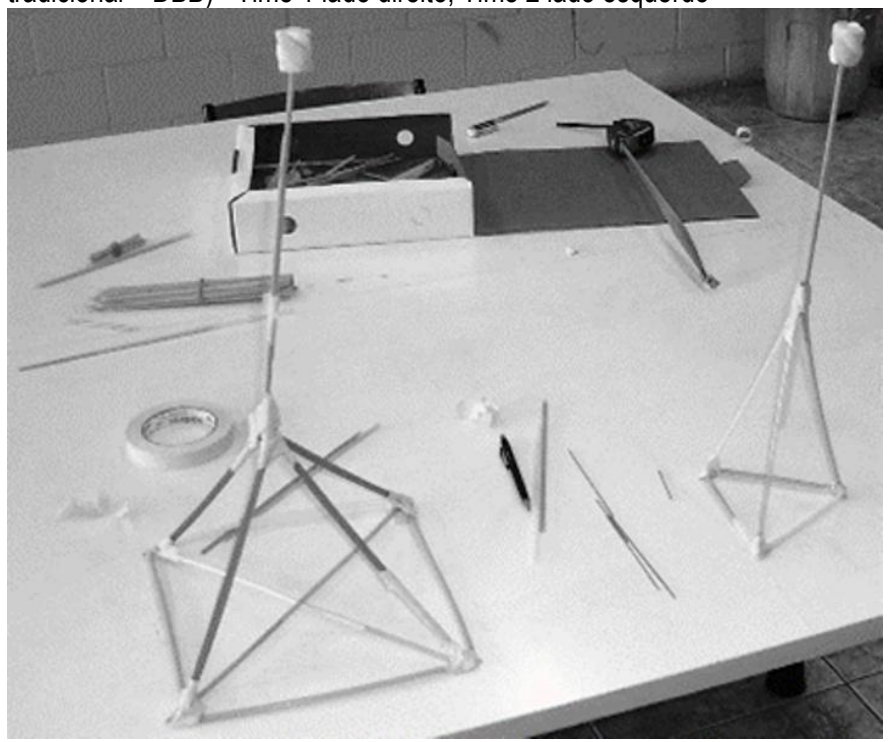

Fonte: Autores.

Figura 4 - Soluções propostas pelos times na segunda rodada (TVD) - Time 1 lado direito, Time 2 lado esquerdo

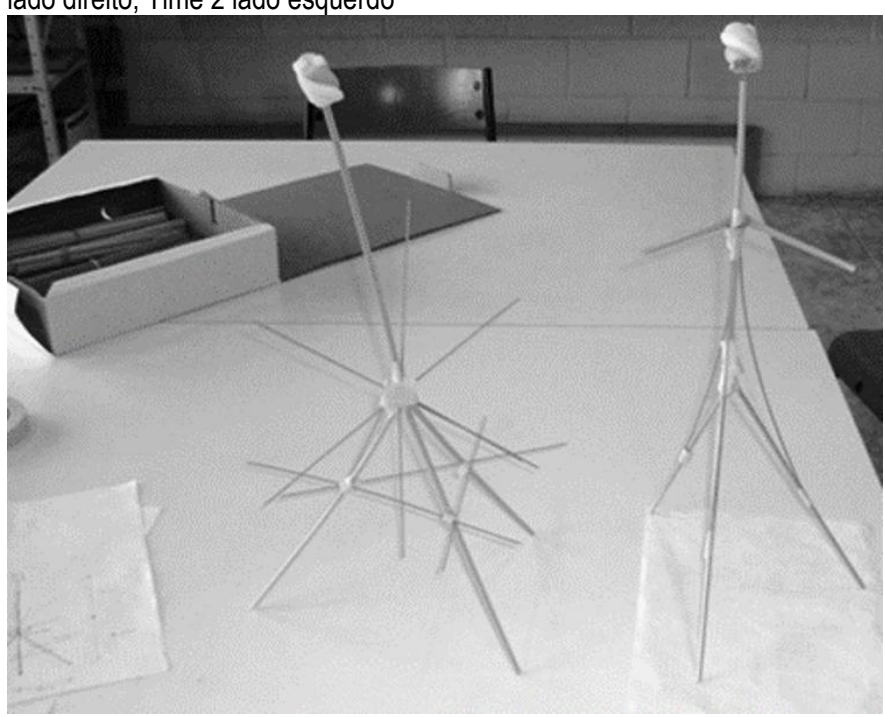

Fonte: Autores.

\section{Simulações na empresa de incorporação imobiliária}

Novas simulações foram realizadas em uma empresa que atua no mercado de incorporação imobiliária residencial e comercial de uso misto e larga escala, desenvolvimento e administração de shoppings centers e hotéis de alto padrão. O segmento de atuação diversificado foi um dos fatores que levou à seleção da empresa.

A simulação contou com diversos agentes, quais sejam, projetistas de diversas especialidades, trainee, orçamentistas e coordenadores de incorporação. Os participantes foram divididos em dois times, de forma aleatória (os participantes sentaram-se aleatoriamente, antes de qualquer conhecimento sobre a simulação e sua participação se deu conforme a disponibilidade dos profissionais para participar das simulações). Cada time teve metade dos seus participantes atuando no grupo de projetistas e a outra metade no grupo de construtores. Um pesquisador atuou como cliente do projeto. O Quadro 1 contém a descrição dos times: (cada cargo representando um participante)

Quadro 1 - Descrição dos participantes dos dois times

\begin{tabular}{|c|c|c|}
\hline Papel de atuação na simulação & Formação & Cargo na empresa \\
\hline \multicolumn{3}{|c|}{ Participantes do Time 1} \\
\hline \multirow{3}{*}{ Projetistas } & \multirow{3}{*}{ Arquiteto } & Projetista externo \\
\hline & & Projetista externo \\
\hline & & Coord. Incorporação \\
\hline \multirow{3}{*}{ Construtores } & \multirow{3}{*}{ Arquiteto } & Orçamentista \\
\hline & & Coordenador de projetos \\
\hline & & Orçamentista \\
\hline \multicolumn{3}{|c|}{ Participantes do Time 2} \\
\hline \multirow{3}{*}{ Projetistas } & \multirow{3}{*}{ Arquiteto } & Coordenador de projetos \\
\hline & & Coordenador de projetos \\
\hline & & Coord. Incorporação \\
\hline \multirow{3}{*}{ Construtores } & \multirow{3}{*}{ Arquiteto } & Trainee \\
\hline & & Orçamentista \\
\hline & & Coordenador de projetos \\
\hline
\end{tabular}

Fonte: Autores.

Assim como nas simulações-piloto no ambiente acadêmico, a temática sobre custos não foi apresentada na primeira rodada (DBB). Os parâmetros e as restrições de projeto foram exibidos aos participantes, bem como o formulário com as dimensões dos componentes disponíveis para construção. $\mathrm{O}$ tempo total incluindo projeto e construção da torre foi de $30 \mathrm{~min}$, que poderiam ser utilizados livremente pelos grupos, desde que não fosse ultrapassado. 
Depois do projeto elaborado, os desenhos do projeto foram aprovados pelo cliente e posteriormente entregues aos construtores, dentro de cada grupo. As Figuras 5 a 9 apresentam as soluções dos times na primeira rodada (DBB). A Figura 10 apresenta as soluções da segunda rodada (TVD) .

\section{Discussões da rodada 1 na empresa de incorporação} imobiliária - processo tradicional (DBB)

Ambos os times excederam o prazo estipulado (30 min) para o projeto e construção da torre. Além disso, os dois times enfrentaram problemas de construtibilidade nessa primeira rodada da simulação, pois havia o comprometimento com a entrega de valor ao cliente.

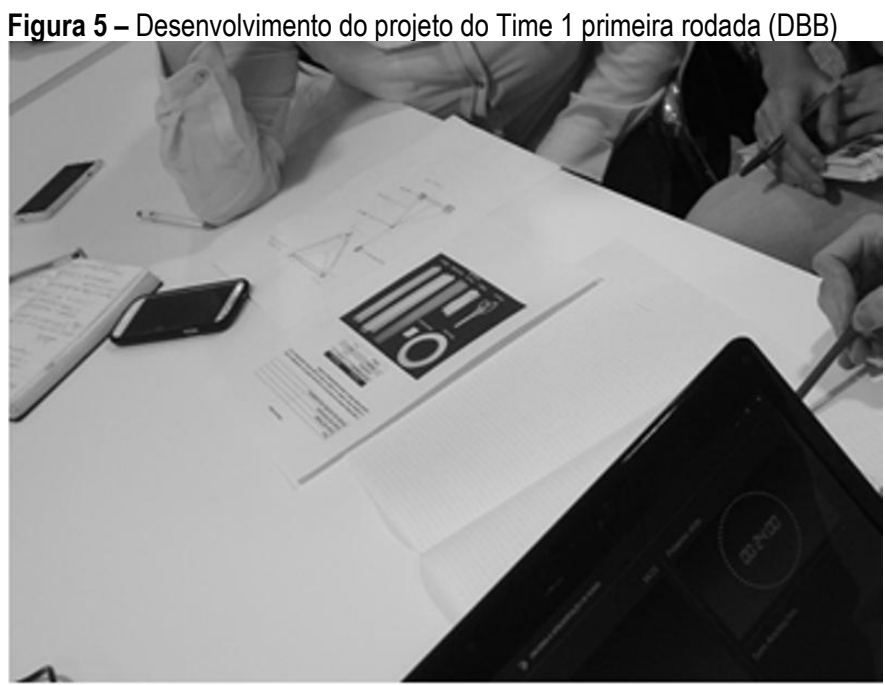

Fonte: Autores.

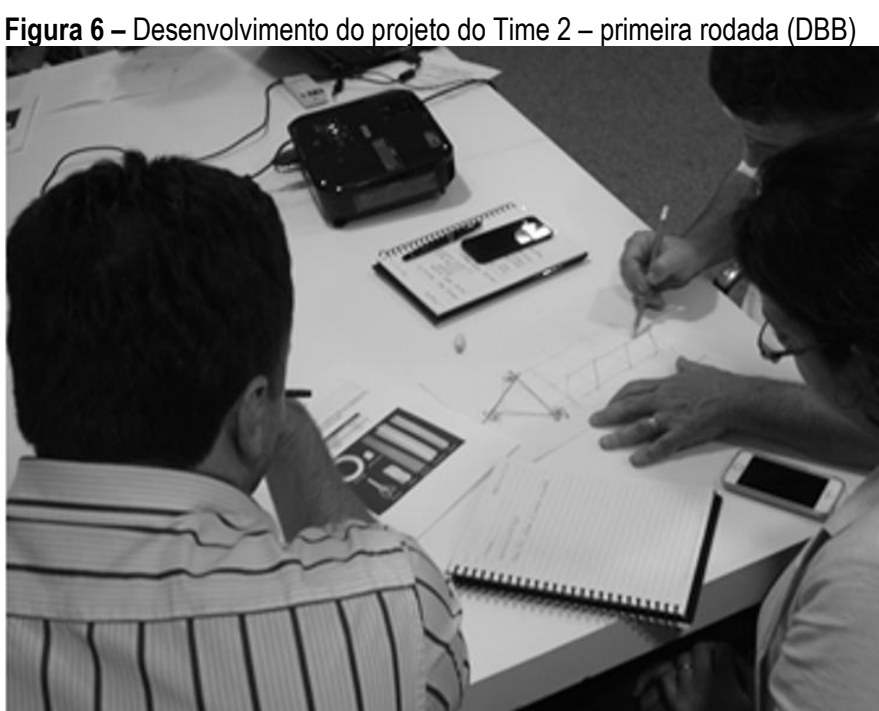

Fonte: Autores.
Conforme já visto nas simulações-piloto no meio acadêmico, uma das demandas do cliente era de que houvesse algum detalhe arquitetônico no projeto que remetia a torre a um marco icônico. A equipe de construtores do time 2 não conseguiu construir justamente este detalhe arquitetônico desenvolvido pelos projetistas, pois a construção desse detalhe comprometia a estabilidade da torre. Por outro lado, a equipe de construtores do time 1 conseguiu construir o detalhe arquitetônico previsto no projeto. Porém, a altura da torre construída foi superior a $50 \mathrm{~cm}$. A Tabela 3 mostra os custos das duas rodadas (DBB e TVD) para os dois times

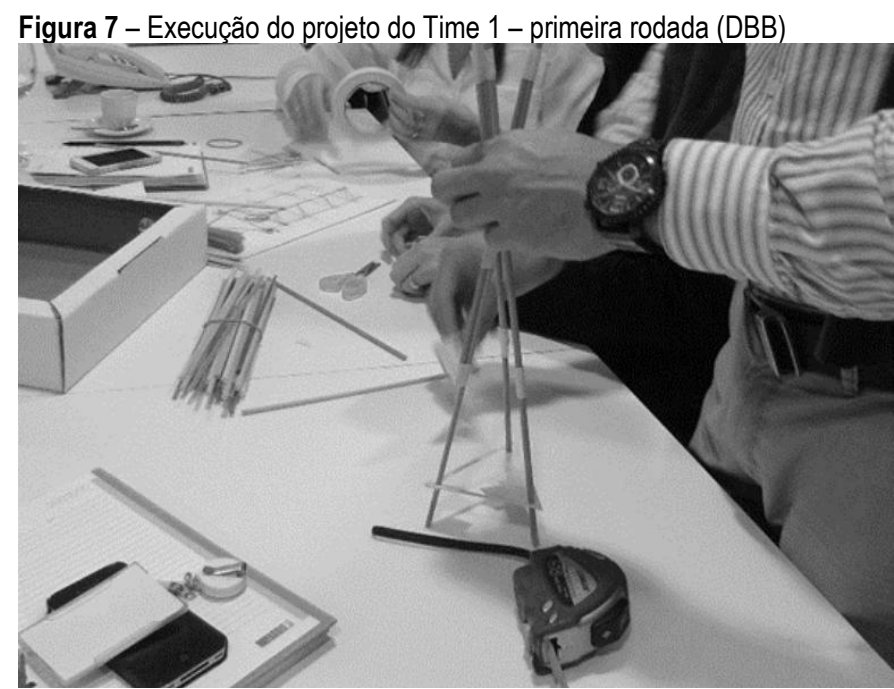

Fonte: Autores.

Figura 8 - Execução do projeto do Time 2 - primeira rodada (DBB)

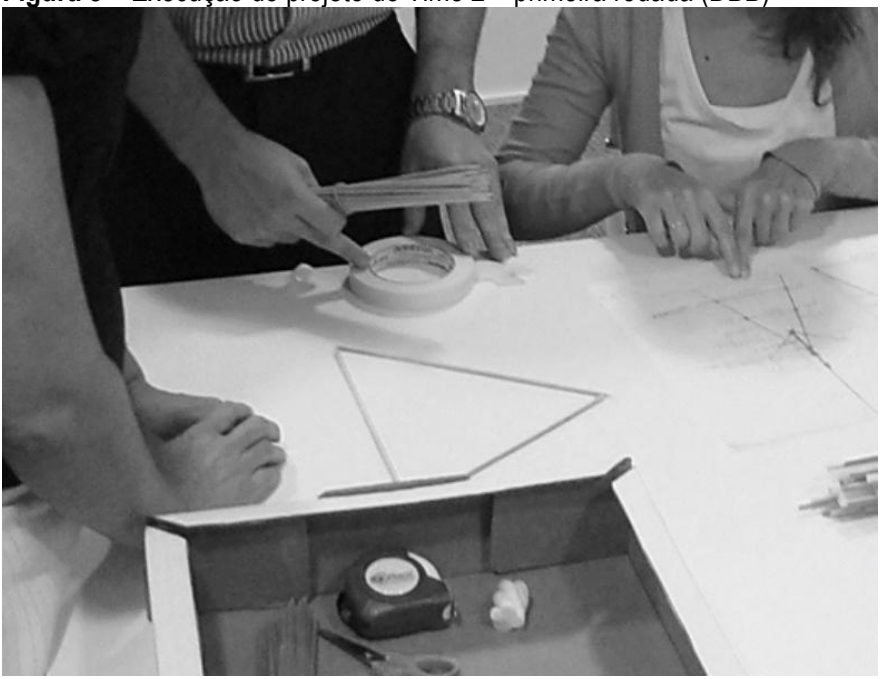

Fonte: Autores. 
Figura 9 - Soluções propostas pelos times na primeira rodada (DBB) - Time 1 lado esquerdo, Time 2 lado direito

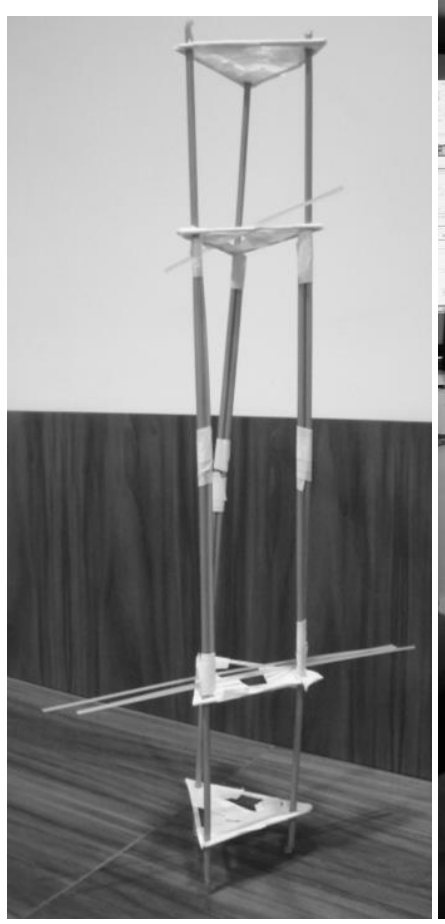

Fonte: Autores.

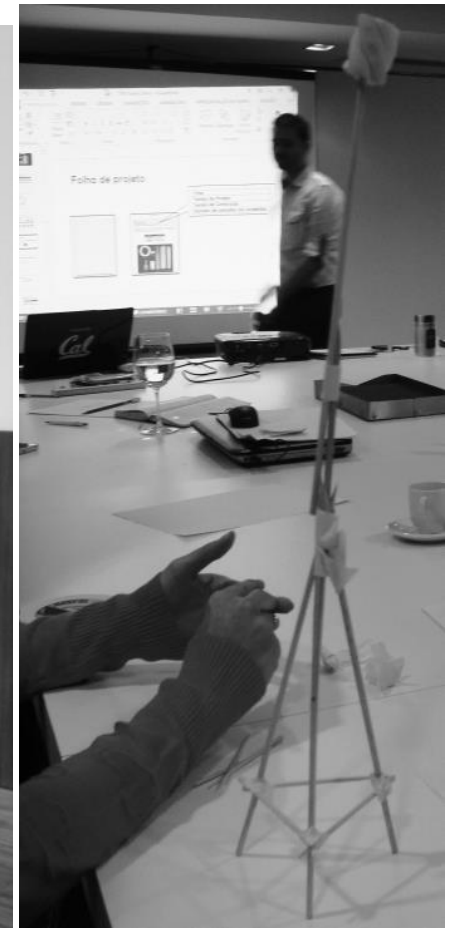

Figura 10 - Soluções propostas pelos times na segunda rodada (TVD) Time 1 lado direito, Time 2 lado esquerdo

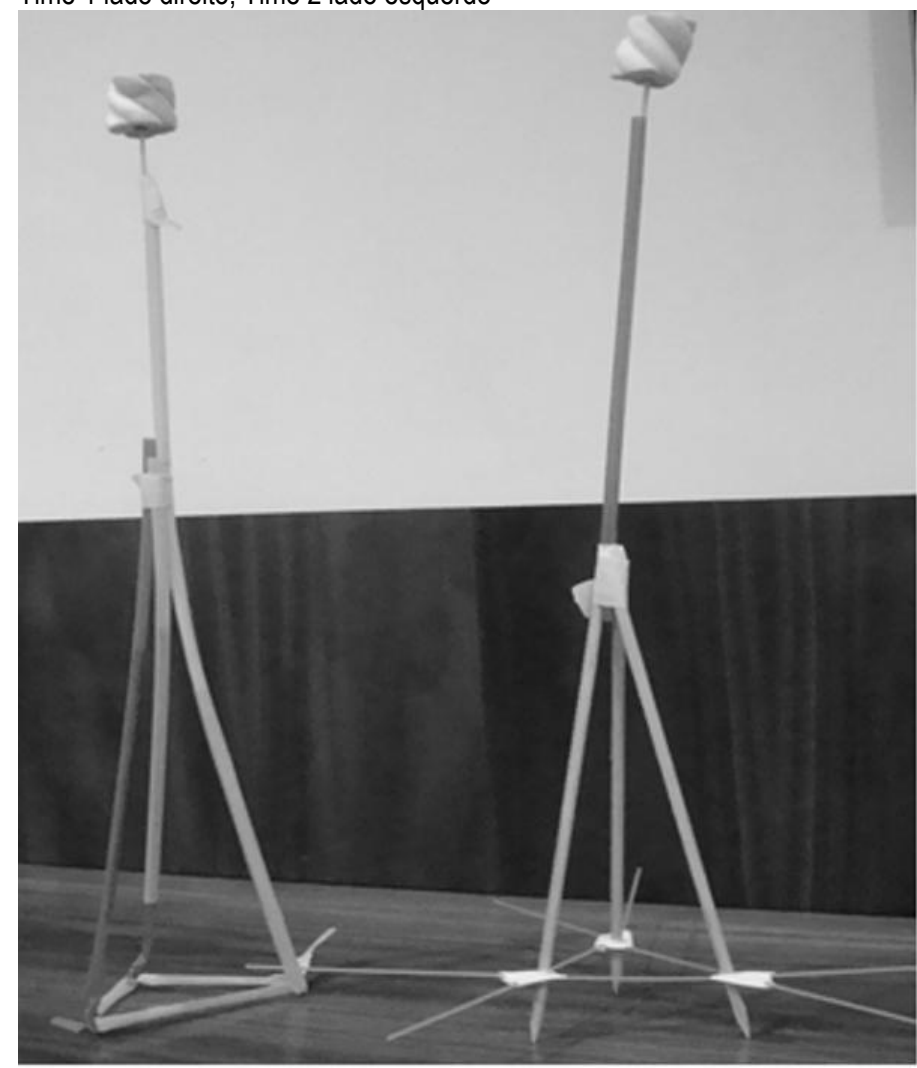

Fonte: Autores.

Tabela 3 - Custos das soluções projetuais das simulações na empresa de incorporação imobiliária

\begin{tabular}{|c|c|c|c|c|c|c|c|c|c|}
\hline \multirow{3}{*}{ Materiais } & \multirow{3}{*}{$\begin{array}{l}\text { Custo } \\
\text { unitário } \\
\text { (UM\$) }\end{array}$} & \multicolumn{4}{|c|}{ Primeira Rodada - tradicional (DBB) } & \multicolumn{4}{|c|}{ Segunda Rodada - TVD } \\
\hline & & \multicolumn{2}{|c|}{ TIME 1} & \multicolumn{2}{|c|}{ TIME 2} & \multicolumn{2}{|c|}{ TIME 1} & \multicolumn{2}{|c|}{ TIME 2} \\
\hline & & $\begin{array}{l}\text { Número de } \\
\text { unidades }\end{array}$ & $\begin{array}{l}\text { Subtotal } \\
\text { (UM\$) }\end{array}$ & $\begin{array}{l}\text { Número de } \\
\text { unidades }\end{array}$ & $\begin{array}{l}\text { Subtotal } \\
\text { (UM\$) }\end{array}$ & $\begin{array}{l}\text { Número de } \\
\text { unidades }\end{array}$ & $\begin{array}{c}\text { Subtotal } \\
\text { (UM\$) }\end{array}$ & $\begin{array}{l}\text { Número de } \\
\text { unidades }\end{array}$ & $\begin{array}{c}\text { Subtotal } \\
\text { (UM\$) }\end{array}$ \\
\hline Fio de espaguete & 1,00 & 0 & - & 6 & 6,00 & 3 & 3,00 & 4 & 4,00 \\
\hline Palito & 5,00 & 3 & 15,00 & 12 & 60,00 & 0 & - & 0 & - \\
\hline Canudo & 2,00 & 0 & - & 9 & 18,00 & 6 & 12,00 & 1 & 2,00 \\
\hline Espeto & 3,00 & 5 & 15,00 & 9 & 27,00 & 0 & - & 3 & 9,00 \\
\hline Fita crepe (por junta) & 0,50 & 5 & 2,50 & 21 & 10,50 & 4 & 2,00 & 4 & 2,00 \\
\hline Subtotal & & & 32,50 & & 121,50 & & 17,00 & & 17,00 \\
\hline
\end{tabular}

Além de simular o projeto e a construção de uma torre no contexto tradicional em que o custo é um parâmetro de saída do processo de projeto, a primeira rodada do jogo (DBB) teve como objetivo promover uma discussão sobre as dificuldades enfrentadas. Neste momento, o facilitador elencou as seguintes perguntas aos participantes que atuaram como projetistas: i) A construtibilidade da torre foi levada em consideração durante o projeto?, ii) O custo da torre foi levado em consideração durante o projeto?, iii) Os projetistas pensaram no grau de compreensão do projeto pelos executores? Reflexões pergunta i): as respostas dos participantes mostraram que havia falta de conhecimento sobre os materiais, por parte dos projetistas, dificultando a visão sobre construtibilidade do modelo. Reflexões pergunta ii): o desconhecimento com relação aos custos dos materiais utilizados, levou a uma desconsideração acerca do custo da torre, já que os custos dos materiais eram desconhecidos também. Reflexões pergunta iii): as diversas consultas dos executores aos projetistas mostraram que o projeto não ficou tão claro para grupo de execução da torre. .

Além disso, os participantes que atuaram como construtores também foram questionados em relação aos seguintes itens: iv) o projeto contemplou aspectos de construtibilidade?, v) qual foi o grau de compreensão do projeto?, vi) o que acharam do tempo para construção 
da torre, após receberem o projeto para execução? Reflexões pergunta iv): o fato de várias consultas terem sido necessárias, mostra que a falta de conhecimento sobre os materiais por parte dos projetistas mitigou o grau de compreensão de construtibilidade do modelo. Reflexões pergunta v): o grau de compreensão do projeto também não foi total, já que, conforme citado, várias consultas foram feitas ao grupo de projeto, por parte dos executores. Reflexões pergunta vi): ambas equipes acharam o tempo insuficiente para a execução, considerando que os projetistas utilizaram mais da metade do tempo disponível para o projeto. Além de nortear a discussão, essas perguntas tiveram como objetivo identificar se as dificuldades que emergiram durante a primeira rodada (DBB) também são enfrentadas no dia a dia da empresa, e as respostas foram positivas com relação à semelhança entre a realidade profissional vivenciada no dia a dia dos participantes.

\section{Discussões da rodada 2 na empresa de incorporação imobiliária - TVD}

Utilizou-se o mesmo benchmarking de custo permissível das simulações-piloto no meio acadêmico, ou seja, UM\$21,00. Os dois times entregaram a torre antes do prazo total estipulado (30 min.) e abaixo do custo permissível estipulado. A integração entre a equipe de projeto e construção presente nesta rodada eliminou as dificuldades enfrentadas na primeira rodada, tais como construtibilidade e baixa compreensão do projeto.

Assim como na primeira rodada, houve uma discussão com projetistas e construtores com base nas questões apontadas anteriormente. Esta discussão também buscou identificar potenciais barreiras para aplicação do TVD na situação analisada. Tendo como base suas experiências práticas, os participantes elencaram algumas barreiras para aplicação do TVD, que exigiriam mudanças organizacionais e culturais para serem suplantadas: i) custo do envolvimento de fornecedores e subempreiteiros-chave no início do processo de projeto; ii) falta de parcerias com fornecedores $\mathrm{e}$ subempreiteiros-chave; iii) pouco tempo para desenvolvimento do projeto.

\section{Reflexões e contribuições teóricas a partir da aplicação do jogo}

Além da compreensão de princípios básicos do TVD, a aplicação do jogo permitiu revelar alguns pressupostos tácitos de arquitetos e projetistas acerca do TVD. A partir do custo permissível definido na segunda rodada (TVD), os dois times apresentaram soluções projetuais aparentemente mais simplificadas, quando comparadas àquelas apresentadas na primeira rodada (DBB). Duas questões para novos estudos emergiram desta constatação: i) o custo como parâmetro de entrada no projeto necessariamente induz simplificações projetuais?, ii) este é um modelo mental genérico dos projetistas?

Um dos participantes do jogo relatou que a prédeterminação da restrição de custo limitava sua criatividade durante a fase de concepção do projeto. A percepção desse participante foi de que a segunda rodada (TVD) simulava o contexto de um programa de provisão de habitação de interesse social. Em contraponto, Rybkowski et al. (2011) investigaram possíveis correlações entre a estética e o custo de objetos. A pesquisa concluiu que se verificou pouca correlação entre a preferência estética dos participantes das opções apresentadas e o respectivo custo de fabricação.

Savage e Miles (1998) conduziram um experimento, onde quatro restrições foram impostas para os participantes realizarem três tarefas projetuais. As restrições incluíam: i) externa: tempo e custo, ii) interna: conhecimento, experiência e discernimento e iii) inerente à tarefa: características físicas, como limitação de espaço e altura. A tarefa dos projetistas foi elaborar um artefato adequado utilizando os materiais disponíveis. $\mathrm{O}$ resultado demonstrou uma redução do número de soluções para as tarefas projetuais, devida às restrições impostas (Figura 11).

Figura 11 - Número possível de soluções para determinada tarefa projetual

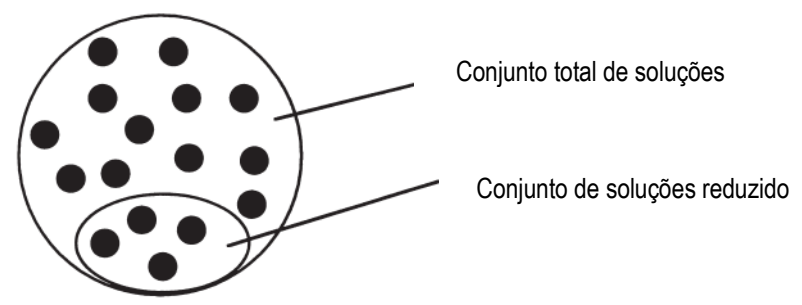

Fonte: Adaptado de Savage e Miles (1998)

Portanto, a diminuição na quantidade de soluções não necessariamente representa um fator que induz à simplificação. A existência de parâmetros restritivos, tais como custo e tempo, conduz para uma mudança de referência de "o que é possível construir com o material disponível" para "como se pode construir algo funcional de forma mais econômica" (SAVAGE; MILES, 1998). O mesmo experimento demonstrou que, quando as restrições externas são removidas (custo e tempo, por exemplo), nem sempre as melhores soluções para a tarefa dada são geradas, no entanto estas restrições devem ser mantidas no mínimo necessário (SAVAGE; MILES, 1998). 


\section{Conclusão}

A análise dos resultados revela algumas questões que instigam reflexão. A primeira delas se refere ao custo como restrição, presente frequentemente em empreendimentos do setor. Os resultados provenientes da segunda rodada (TVD), na qual foi imposta uma restrição de custo, acabaram levando a uma aparente simplificação do modelo.

O porquê desta ocorrência justifica pesquisas futuras no assunto. Os custos necessariamente conduzem a simplificações e limitam o processo criativo, ou trata-se de um modelo mental comum nas atividades projetuais, que pode ser revisto à luz dos conceitos do TVD, qual seja, a de que estas restrições podem ser indutoras de criatividade e inovação?

O TVD demanda mudanças no processo de projeto, e uma das mais desafiadoras é considerar o custo como parâmetro de entrada no processo, em vez de ser uma mera consequência do mesmo. Somando-se a isso, o processo de projeto nas empresas apresenta grande fragmentação, enquanto que no TVD, buscam-se práticas integradas e colaboração, em prol do projeto como um todo, e não baseado apenas nas agendas de interesses individuais dos participantes em um dado empreendimento.

Implantações completas de novas tecnologias e processos gerenciais implicam em grandes desafios, pois a percepção sobre os riscos envolvidos é alta. Além disso, há necessidade de mudanças de práticas muitas vezes já arraigadas em determinadas atividades profissionais. A presente simulação pode ser uma abordagem promissora para conscientizar as empresas da viabilidade de adoção de novos processos e tecnologias, num ambiente livre de riscos, no caso, a adoção dos conceitos do TVD no processo de projeto.

A quantidade de simulações é uma das limitações da pesquisa. A discussão sobre eventuais correlações entre julgamentos estéticos e os custos dos modelos desenvolvidos está além do escopo deste artigo. Sugerese que estes aspectos sejam objetos de pesquisas futuras.

As simulações foram feitas de forma sequencial, o que pode representar um viés devido ao processo de aprendizado vivenciado pelos participantes da rodada 1 (tradicional - DBB) para a 2 (TVD). Assim, recomendam-se novos estudos utilizando-se a simulação paralela, em lugar da sequencial. No entanto, esta abordagem também pode apresentar dificuldades, pois seriam necessários dois grupos perfeitamente homogêneos para que os resultados de grupos diferentes possam ser comparados sem viés.

Por fim, também seria interessante incluir elementos representativos de licitação de empreendimentos pelo menor preço na simulação do processo tradicional (DBB).

\section{Agradecimentos}

Os autores agradecem à CAPES e à FAPESP pelo apoio financeiro, bem como aos alunos, docentes, profissionais e à empresa que participaram das simulações descritas neste artigo.

\section{Referências}

AIA (The American Institute of Architects). Integrated Project Delivery: A Guide. 2007. Disponível em: http://www.aia.org/contractdocs/aias077630. Acesso em: Jun. 2014.

BALLARD, Glenn. The last planner system of production control. 2000. 192f. Tese (Doutorado) - School of Civil Engineering, The University of Birmingham, Birmingham, 2000.

BALLARD, Glenn; REISER, Paul. The St. Olaf College Fieldhouse project: a case study in designing to target cost. In: ANNUAL CONFERENCE OF THE INTERNATIONAL GROUP FOR LEAN CONSTRUCTION, 12, 2004, Helsingor. Proceedings .... Helsingor: IGLC, 2004. Disponível em: http://www.iglc.net/papers/Details/325. Acesso em: Jun. 2014.

BALLARD, Glenn. Target value design: current benchmark. Lean Construction Journal , 2011. p. 79-84. Disponível em: http://www.leanconstruction.org/media/docs/lcj/2011/LCJ_11_009.pdf. Acesso em: Jun. 2014.

GERON, Luciana Cristina. Notas sobre concepções de preço e valor nos custos da Arquitetura. 2011. Dissertação (Mestrado em Arquitetura, Urbanismo e Tecnologia) - Escola de Engenharia de São Carlos, Universidade de São Paulo, São Carlos, 2011. Disponível em: http://www.teses.usp.br/teses/disponiveis/18/18141/tde-07072011-104055/. Acesso em: 2015-06-12.

COOPER, Robin; SLAGMULDER, Regine. Target Costing and Value Engineering. Portland, USA: Productivity Press, 1997. 
DENEROLLE, Stéphanie. The application of Target Value Design to the design phase of 3 hospital projects. Technical Report. Project Production Systems Laboratory. University of California, Berkeley. Janeiro, 2013.

DO, D.;CHEN, C.;BALLARD, G; TOMMELEIN, I. Target Value Design as a Method for Controlling Project Cost Overruns. In: ANNUAL CONFERENCE OF THE INTERNATIONAL GROUP FOR LEAN CONSTRUCTION, 22., 2004, Oslo. Proceedings .... Oslo: IGLG, 2004. Disponível em: http://www.iglc.net/Papers/Details/1065. Acesso em: Jun. 2014.

FELLOWS, R.; LIU, A. Research Methods for Construction. Wiley-Blackwell, 2008.

JACOMIT, Ana Mitsuko; GRANJA, Ariovaldo Denis. An investigation into de adoption of target costing on Brazilian public social housing projects. Architectural Engineering and Design Management, v. 7, n. 2, p. 113-127, 2011. http://dx.doi.org/ 10.1080/17452007.2011.582334http:/

LIKER, Jeffrey K. The Toyota Way. 14 Management Principles from the World’s Greatest Manufacturer. Estados Unidos: McGraw-Hill, 2004.

MACOMBER, H.; HOWELL, G.; BARBERIO, J. Target-Value Design: Nine Foundational Practices for Delivering Surprising Client Value. Lean Project Consulting, 2007. Disponível em: http://www.leanconstruction.org/media/docs/3Target-Value-Design-LPC.pdf

MELHADO, Silvio; EVETTE, Thérèse; HENRY, Eric; FABRICIO, Márcio Minto; SEGNINI Jr., Francisco; LAUTIER, François. Uma perspectiva comparativa da gestão de projeto de edificações no Brasil e na França. Gestão e Tecnologia de Projetos. São Carlos, v.1, n.1, novembro 2006.

MUNANKAMI; Manish B. Development and Testing Of Simulation (Game) To Illustrate Basic Principles Of Integrated Project Delivery And Target Value Design: A First Run Study. 2012. Dissertação (Mestrado) - Texas A\&M University, 2012, College Station.

ROMANO, Fabiane V. Modelo de Referência para o Gerenciamento do Processo de Projeto Integrado de Edificações. 2003. 326 p. Tese (Doutorado) - Programa de Pós-Graduação em Engenharia de Produção, Universidade Federal de Santa Catarina, Florianópolis.

RYBKOWSKI, Z. K.; MUNANKAMI, M.; GOTTIPATI, U.; FERNANDEZ-SOLIS, J.; LAVY, S. Toward an understanding of cost and aesthetics: Impact of cost constraints on aesthetic ranking following target value design exercises. In: ANNUAL CONFERENGE OF THE INTERNATIONAL GROUP FOR LEAN CONSTRUGTION, 19., 2011, Lima. Proceedings ... Lima: IGLC, 2011, p. 448-457. Disponível em: http://www.iglc.net/Papers/Conference/21. Acesso em: Jun. 2014

PENNANEN, Ari; BALLARD, Glenn; HAAHTELA, Yrjänä. Designing to targets in a target costing process. In: ANNUAL CONFERENCE OF THE INTERNATIONAL GROUP FOR LEAN CONSTRUCTION, 18., 2010, Haifa. Proceedings ... Haifa: IGLC, 2010. Disponível em http://www.iglc.net/Papers/Details/675. Acesso em: Jun. 2014.

PISHDAD-BOZORGI, Pardis; MOGHADDAM, Ehsan Hamzanlui; KARASULU, Yilmaz. Advancing Target Price and Target Value Design Process in IPD Using BIM and Risk-Sharing Approaches. In: ASC ANNUAL INTERNATIONAL CONFERENCE \& CIB COMMISSION W089, 49., 2013, San Luis Obispo. Proceedings ... San Luis Obispo: ASC, 2013.

SAVAGE; Justin C. D, MILES; Christopher. The interaction of time and cost constraints on the design process. Design Studies. v. 19, n. 2, p. 217-233, abr. 1998.

ZIMINA, Daria; BALLARD, Glenn; PASQUIRE, Christine. Target value design: using collaboration and a lean approach to reduce construction cost. Construction Management and Economics, v. 30, n. 5, p. 383-398, abr. 2012. http://dx.doi.org/ 10.1080/01446193.2012.676658

\section{${ }^{1}$ Carolina Asensio Oliva}

Arquiteta Urbanista. Mestre em Arquitetura. Endereço postal: Avenida Albert Einstein, 951, Cidade Universitária “Zeferino Vaz" - Barão Geraldo - Campinas, SP, Brasil, 13083-852

\section{${ }^{2}$ Reymard Savio Sampaio de Melo}

Engenheiro Civil. Mestre em Engenharia Civil. Endereço postal: Avenida Albert Einstein, 951, Cidade Universitária "Zeferino Vaz" - Barão Geraldo - Campinas, SP, Brasil, 13083-852

\section{${ }^{3}$ Ariovaldo Denis Granja}

Engenheiro Civil. Doutor em Engenharia Civil. Endereço postal: Avenida Albert Einstein, 951, Cidade Universitária

"Zeferino Vaz" - Barão Geraldo - Campinas, SP, Brasil, 13083-852 